006 POSTNATAL VARIATION IN VISCOSITY AND HEMATOCRIT OF 6 POLYCYTHEMIC AND NORMAL INFANTS: IMPLICATIONS FOR DIAGNOSIS. RS Ramamurthy, (Spon. by C Grose) ) Univ Prompted by the need for standardization of diagnostic parameters for neonatal polycythemia-hyperviscosity syndrome 89 infants were studied with parental consent. Cord and peripheral venous (PV) blood sampling was done at 2,6,12 and $18 \mathrm{hrs}$ of age. 16 infants with PV hct $>64 \%$ were considered polycythemic. viscosity was determined at shear rate $11.5,23 \& 46 \mathrm{sec}^{-1}$ with a Wells Brookfield viscometer and hct was measured in duplicate.

In normal infants the mean $\pm 2 S D$ hct rises from cord value of $49 \pm 8 \%$ to $2 \mathrm{hr}(54 \pm 10), 6 \mathrm{hr}(53 \pm 10)$ and $12 \mathrm{hr}(52 \pm 10)(p<.01)$ and drops at $18 \mathrm{hr}(50+10)$. The viscosity remained constant and the best correlation with hct was at 2 and 18 hrs $(r=.6)$. In the polycythemics the hct rises from a cord value of $57 \pm 4$ to 2 $\mathrm{hr}(66 \pm 4), 6 \mathrm{hr}(64 \pm 4, \mathrm{p}<.01)$ and drops at $12 \mathrm{hr}(60 \pm 6)$ and 18 $\mathrm{hr}(60 \pm 8)$. The PV viscosity rises from cord value of $(9 \pm 8)$ cps to $2 \mathrm{hr}(12 \pm 4)$ but drops at $6 \mathrm{hr}(11 \pm 4)$ and $12 \mathrm{hr}(10 \pm 4)$, rising again at $18 \mathrm{hr}(13 \pm 6$, p<.01). Only 6 of 16 polycythemics had PV hct $>64 \%$ beyond $18 \mathrm{hrs}$. All were asymptomatic.

Cord blood hct $>50 \%$ is a good screening procedure to select infants for PV blood sampling. In polycythemic infants the hct and viscosity peak by 2 to 6 hrs, hence PV sampling should be done by $6 \mathrm{hrs}$. In asymptomat ic infants PV sampling should be repeated after $18 \mathrm{hrs}$ and viscosity should be determined before therapeutic decisions are made.

907 TREATMENT OF PEIVIC SARCOMA IN CHILDREN: EXPERIENCE Carey, B.A., Loulse Schnaufer, M.D., Philip Littman, M.D., and Jane Chatten, M.D. The Children's Cancer Research Center (CCRC) of the Children's Hospital of Philadelphia and Department of Pediatrics, University of Pennsylvania, Philadelphia, PA 19104.

Seven children aged 2-16 years with sarcomas arising in the retroperitoneum or pejvis (not in bladder or prostate) were treated at the CCRC from 1974-1983. 6 presented with abdominal distention the che pain and distention and a palpable mass; the other had lung metastases. weight loss. 5 had localized tumors, and 2 had lung metastases. Median primary tumor diameter was $15 \mathrm{~cm}$. All pts underwent exploratory laparotomy and biopsy; none had complete excision. venous vincristine, actinomycin D, and cyclophosphamide; 5 also received Adriamycin. Four pts responded completely and 2 of them survive free of recurrence at 1.5 and $7.5 \mathrm{yrs}$. The other 5 pts died of tumor 2-62 months (med, 18 mos) from diagnosis after pts died of tumor $(3 \mathrm{pts})$ or distant (2 pts) recurrence. By contrast, all 5 local (3 pts) or distant (2 pts) recurrece. the CCRC from 1974pts with bladder-prostate sarcoma treated at the CCRC from $1974-$
1983 are free of recurrence at $1.3-8.7$ yrs (med, 4.3 yrs). These 5 pts presented with acute urinary obstruction and had smaller tumors, without metastases. We conclude that retroperitoneal-pelvic sarcoma is a particularly lethal form of childhood cancer, because it is advanced at diagnosis; local control is difficult due to large tumor size.

Supported in part by Grants CA-14489 and CA-19372 from the National Cancer Institute.
BONE INFARCTTON, OR OSTEOMYELITIS IN CHILDREN WITH SICKLE CELL DISEASE: BONE AND BONE MARROW SCAN 909 FINDINGS. S.P. RAO, N. SOLOMON, S. MILLER, and
DUNN. (Sponsored by L. Finberg). Dept. of Pediatrics and Nuclear Medicine. SUNY, Downstate Med. Ctr., Brooklyn, NY.

Bone infarction (INF) occurs commonly in patients with sickle cell disease (SCD), and is frequently associated with infarction of the bone marrow (INF). Clinically and radiographically it is difficult to distinguish INF from Osteonyelitis (OSTEO). Bone scan using Tc99 diphosphonate \&/or bone marrow scan using Tc99 Sulfur Colloid were done in 33 children (1-16 yrs.) with SCD (SS 32, S-C 1) who had localized bone pain and fever. Twenty-six of 33 patients had INF and 7 had bacteriologically proven OSTEO (Salmonella 5, S. Pneumo 2).

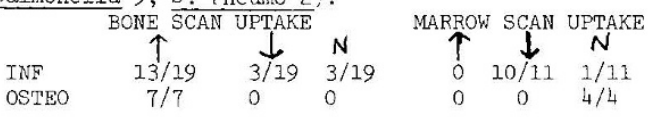

As shown in table, while bone scan uniformly showed increased uptake in OSTEO, uptake was also frequently increased in INF. In contrast, marrow scan demonstrated normal uptake in all four OSTEO patients evaluable; uptake was diminished or absent in 10/11 patients with INF. Thus, in a patient with SCD who has localized bone pain and fever, a normal marr w uptake at the site of pain strongly suggests CSTEO and the need for diagnostic bone aspiration and appropriate therapy. Bone scan appears to be less useful than marrow scan in distinguishing between INF and OSTEO.

\section{$\dagger 910$} IITAMIN B-12 (Cb) AND FOLATE INTERRALATIONSHIP IN A CASE OF HOMOCYSTINURIA-METHYLMALONIC ACID (HC-MMA) -
URIA DUE TO GENETIC CO-FACTOR DEFICIENCY. Yaddanapudi Ravindranath, Ingeborg Krieger. Children's Hospital of MI.,Det. We observed the 9th known case of HC-MMAuria and the 4th with associated megalobloblastic anemia. Treatment accomplished for the first time recovery from biochemical and clinical manifestations in a 2 month old female. The response provided insights into the mechanism of the "folate trap" and the pathogenesis of symptoms. Prior to treatment, plasma folate and $\mathrm{Cb}$ were elesymptoms. Prior to treatment, plasma folate and Cb were eleveticulocytes rose to 7.6 ; urine HC dropped from 3.01 to 1.44 Reticulocytes rose to 7.6 ; urine HC dropped from 3.01 to 1.44
uMol/mg Cr; but MMA did not change $(5.70 \mathrm{mg} / \mathrm{mg} \mathrm{Cr})$. Subsequent uMol/mg Cr; but MMA did not change $(5.70 \mathrm{mg} / \mathrm{mg} \mathrm{Cr})$. Subseque
treatment wi.th (HO) Cb (1000 $\mu \mathrm{g} \mathrm{q.0.d.)} \mathrm{over} 3$ months caused these changes: Higb: 7.2 to $12.8 \mathrm{~g} / \mathrm{dl}$; MCV:117 to 102 ; RBC 2.05 to $3.68 \mathrm{Mill}$; WBC: 3200 to 8000 , head growth from 0.20 to $0.42 \mathrm{~cm} /$ wk; but there was persistent HCuria (1.44-0.76 $\mu \mathrm{Mol} / \mathrm{mg} \mathrm{Cr})$, although MMAuria remained absent. Plasma methionine was low. Oral folate $(2 \mathrm{mg} / \mathrm{d})$ was therefore added. HC disappeared and head growth accelerated further to $0.5 \mathrm{~cm} / \mathrm{wk}$. Methionine supplements caused reappearance of $\mathrm{HC}(0.4 \mathrm{\mu MOl} / \mathrm{mg} \mathrm{Cr})$. After oral betaine $\mathrm{HC}$ was minimal $(0.10 \mu \mathrm{Mol} / \mathrm{mg} \mathrm{Cr})$ and disappeared when folate was increased to $4 \mathrm{mg} / \mathrm{d}$. These observations speak against the existance of a biochemical folate trap, but do not rule out physical trapping of methyltetrahydrofolate due to $\mathrm{cb}$ deficiency. Differences in the resolution of symptoms is attributable to differences in sensitivity of $\mathrm{Cb}$ requiring functions to the deficiency. Co dependant folate transport into cells for demethylation appears to be most sensitive. 908 and Kenneth Bromberg. (Spon. by Audrey Brown)SUNY

908 Downstate Med. Ctr/Kings County Hosp., Brook1yn. Patients infected with Bordetella pertussis frequently exhibit leukocytosis and 1ymphocytosis. Eosinophilia has been noted less frequently. Peripheral blood counts were analyzed in 17 patients with laboratory confirmed pertussis (culture +14 , fluorescence +3) to look for other hematological abnormalities. Fifteen of 17 patients were below the age of one year; others were 4 and 35 years old.

Leukocytosis ( $>15,000 / \mathrm{cmm})$ was noted in 12 patients; 11 of these also had 1ymphocytosis $(>10,000 / \mathrm{cmm})$. Five patient were neutropenic (ANC $<1500 / \mathrm{cmm}$ ). Eosionophilia ( $>500 / \mathrm{cmm}$ ) was noted in 6 patients. No patient had a hemoglobin $<10 \mathrm{gm} / \mathrm{dl}$. was noted in 6 patients. no $(150,000-400,000 / \mathrm{cmm})$ in 15 patients and elevated in 2. Previous investigators have despatients and elevated in 2. Previous investigators have desIn contrast, 5 patients in this study had immature lymphocytes that were medium sized with scanty cytoplasm, loose nuclear chromatin and one or more nucleoli on light microscopy. While the previously described lymphocytosis and eosinophilia were seen, the hematologic findings in pertussis should be expanded to include neutropenia and the presence of immature lymphocytes.

\section{1} CLINICAL AND ULTRASTRUCTURAL CORRELATES OF RECEPTORS FOR PEANUT AGGLUTININ (PNA) IN ACUTE LYMPHOBLASTIC LEUKEMIA (ALL). E.C. Russe11, J.L. Haar, T. Mohanakumar, (Spon. by H.M. Maurer) Medical College of Virginia, partment of Pediatrics, Children's Medical Center, Richmond. Receptors for the lectin PNA have been identified on blast cells from a subpopulation of children with ALL and early data indicated an association between PNA receptors and poor prognosis. Analysis of 174 children with ALL of the non T, non $B$, non pre-B phenotype reveals that $27.6 \%$ have receptors for PNA. There is correlation between presence of PNA receptors and inftial WBC $>100,000$ ( $50 \%$ PNA $)$, age $<2$ years $(40 \%$ PNA $)$ and absence of the common ALL antigen ( $48 \%$ PNA+, cALLa-), a11 features known to predict poor prognosis in childhood ALL.

We used electron microscopy (EM) to characterize the ultrastructure of lymphoblasts. PNAt blasts reveal an electron dense reaction product on the cell surface when agglutinated with PNAconjugated HRP and reacted with DAB. Staining of the cells with uranyl acetate and lead citrate reveals blunt pseudopodia, surface pinocytotic vesicles and irregularly shaped nuclet with lobulated euchromatic chromatin. These features are characteristic of undifferentiated cells and are distinctly different from those EM features of identically prepared blasts lacking the PNA receptor.

We conclude that PNA receptors on blasts correlate with other clinical and immunological predictors of poor prognosis in ALL and that PNA+ blasts have unique ultrastructural features seen in immature, undifferentiated lymphoid cells. 